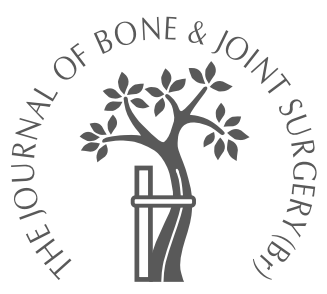

T. Saw,

R. Villar

From the Cambridge

Hip and Knee Unit, Cambridge, England

T. Saw, MA, MRCS,

Research Fellow

R. Villar, MA, FRCS

Consultant Orthopaedic

Surgeon

Cambridge Hip and Knee

Unit, BUPA Cambridge Lea

Hospital, Impington,

Cambridge CB4 9EL, UK.

Correspondence should be sent to Mr T. Saw.

C2004 British Editorial

Society of Bone and

Joint Surgery

doi:10.1302/0301-620X.86B5.

$14836 \$ 2.00$

$J$ Bone Joint Surg [Br] 2004;86-B:655-8.

Received 4 August 2003;

Accepted 3 September 2003

Footballer's hip

\title{
A REPORT OF SIX CASES
}

We have reviewed a consecutive series of six professional footballers who presented with intractable hip pain which was attributed at arthroscopy, to an anterior acetabular labral tear with adjacent chondral damage. The location and type of labral tear were identical for each patient. There was no evidence of acetabular dysplasia. A variable area of chondral damage was associated with the labral tear.

All unstable tissue was resected. Five returned to professional football at the highest level. Acetabular labral pathology should be included in the differential diagnosis of footballers with hip or groin pain. Arthroscopy of the hip is an appropriate method of diagnosis and treatment and minimises the length of rehabilitation required.

The acetabular labrum is a fibrocartilaginous structure attached to the bony rim of the acetabulum and to the transverse ligament. It is triangular in shape with its apex as a free edge extending beyond the midpoint of the femoral head. It increases the surface area of the acetabulum and stabilises the joint.

Football is a sport with physical contact and hip and groin injuries account for a significant loss in training time. Groin injuries (including injuries to adductor muscles, osteitis pubis and suspected hernia) are six times more common than injuries to the hip and the iliopsoas tendon, according to information collated by the English Football Association. ${ }^{1}$ The data show that on average, players with groin injuries take three weeks to return to training, but those with hip injuries take approximately 12 days. Groin and hip injuries encompass a wide variety of differential diagnoses and a definitive diagnosis is often difficult.

Injuries to the acetabular labrum have been previously described as being due to degenerative change $(50 \%)$ or trauma $(20 \%)$; the remainder are said to be idiopathic or congenital. ${ }^{2}$ Athletes form a significant proportion of those presenting with labral pathology secondary to trauma. Axial and torsional repetitive strains bear upon the acetabular labrum. ${ }^{3}$ The use of the arthroscope in the investigation of debilitating hip pain has led to a greater understanding of the nature of labral tears and contributed to their management.

Ito et $\mathrm{al}^{4}$ suggested that labral tears are secondary to an abnormality of the proximal femur, either decreased head/neck offset or a reduction in femoral anteversion. They studied 24 young patients with intractable hip pain. A correlation between abnormal proximal femoral anatomy and labral tears was also observed by Bonnomet et $\mathrm{al}^{5}$ who showed proximal femoral abnormalities in $50 \%$ of a population that underwent arthroscopy. Their patients were older, with a mean age of 39 years (25 to 61), and showed significant chondral pathology in several cases.

\section{Patients and Methods}

The specialised nature of our arthroscopic hip practice recently led to the tertiary referral of six professional footballers who play at the highest level, over a period of six months. All had intractable hip pain which prevented them from training. Several had already undergone extensive periods of rehabilitation or groin surgery. All had labral tears, identified at arthroscopy. These cases prompted us to look more closely into the nature of the injury and its impact on their profession.

We interviewed the players with the medical staff from the clubs involved. We recorded the following information: position on the field, foot dominance, type of boot worn, family history, childhood problems, past medical and surgical history, previous injury, detailed nature of the latest injury, continuing symptoms, limitation in activities of daily living, exacerbating or relieving factors, radiological investigations and current treatment (Table I). Rehabilitation after arthroscopy and date of 
Table I. History of the six footballers

\begin{tabular}{|c|c|c|c|c|c|c|c|}
\hline Player & $\begin{array}{l}\text { Affected } \\
\text { side }\end{array}$ & $\begin{array}{l}\text { Dominant } \\
\text { foot }\end{array}$ & $\begin{array}{l}\text { Position on } \\
\text { the field }\end{array}$ & Action at injury & $\begin{array}{l}\text { Previous injury } \\
\text { or surgery }\end{array}$ & $\begin{array}{l}\text { Provocation } \\
\text { test }\end{array}$ & Recovery time \\
\hline 1 & Right & Right & Midfield & While jogging & Hernia repair & Positive & 15 weeks \\
\hline 2 & Right & Left & Defence & External rotation/hip extended & Groin strain & Positive & 11 weeks \\
\hline 3 & Left & Right & Defence & Direct blow. Hip extended & Hernia repair & Positive & 8 weeks \\
\hline 4 & Right & Right & Forward & Flexed and internally rotated & Hernia repair & Positive & $\begin{array}{l}\text { Light training only } \\
\text { at eight months }\end{array}$ \\
\hline 5 & Left & Right & Midfield & Extended/internally rotated & None & Positive & 13 weeks \\
\hline
\end{tabular}

return to full fitness were also recorded. The players were asked more general questions regarding the level and extent of sporting activity and expectation, and whether this had changed during their career. The medical staff then gave information regarding any changes in playing commitment and the treatment the players had received.

The senior author (RV) examined all players prior to arthroscopy and their response to the provocation test was noted. This test, flexion of the hip to $90^{\circ}$, internal rotation and adduction, is positive if it elicits significant discomfort. It has been shown by several authors to be positive in the presence of a torn labrum. ${ }^{3,6}$ The arthroscopic findings were reviewed for the position and type of labral tear as well as any associated pathology. Within the group there were four right and two left affected hips, with three right and three left-footed players. Only two players had injured

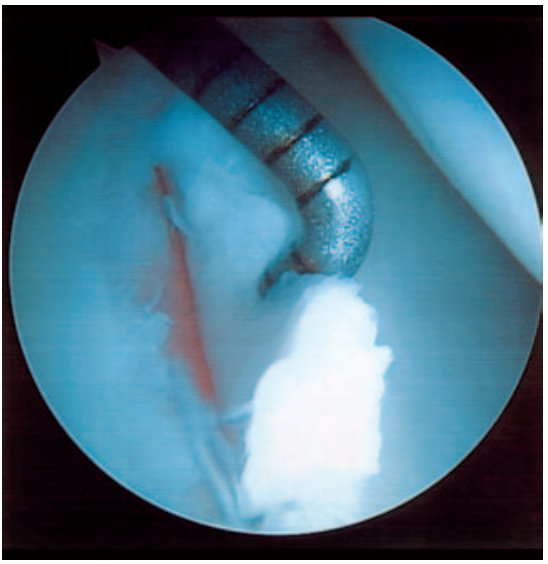

Fig. 1a

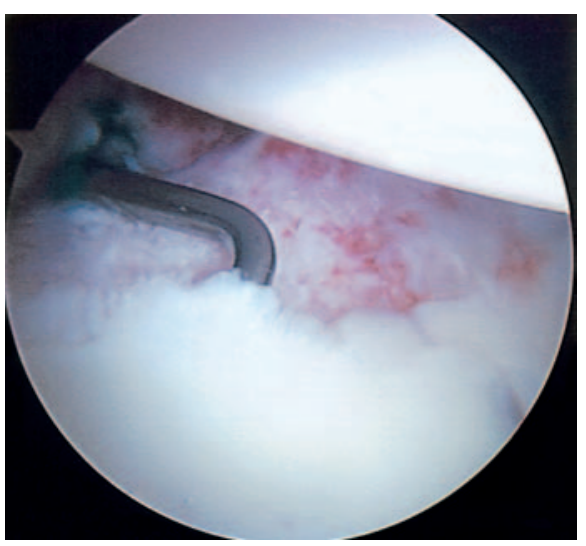

Fig. 1d

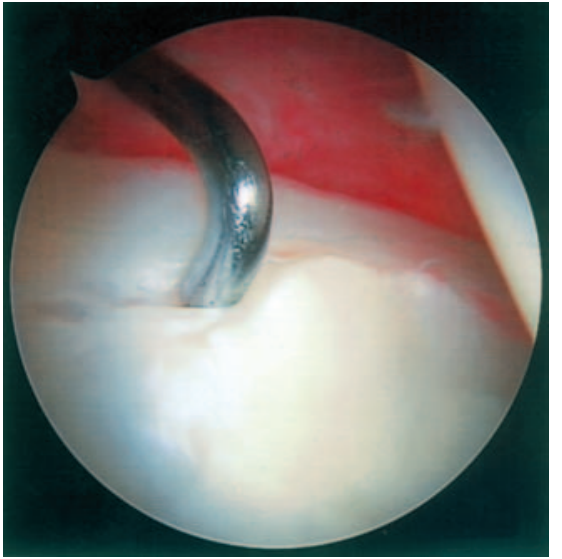

Fig. 1b

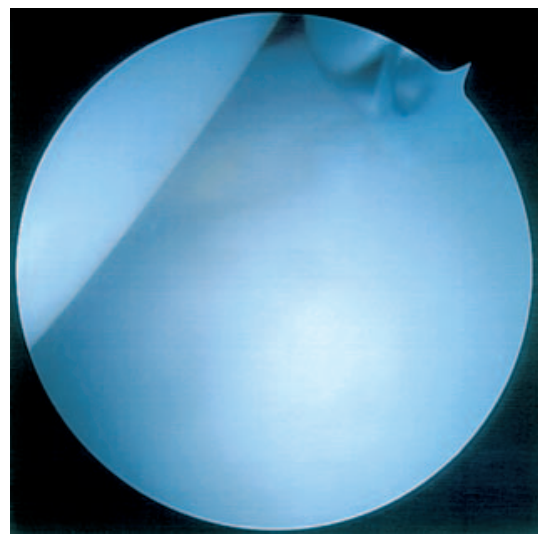

Fig. 1e

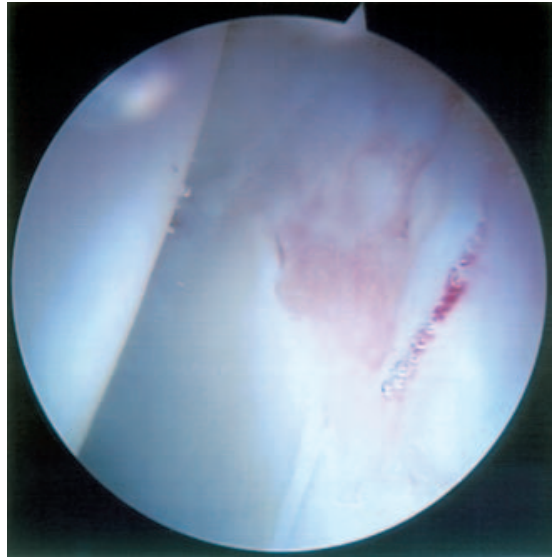

Fig. 1c

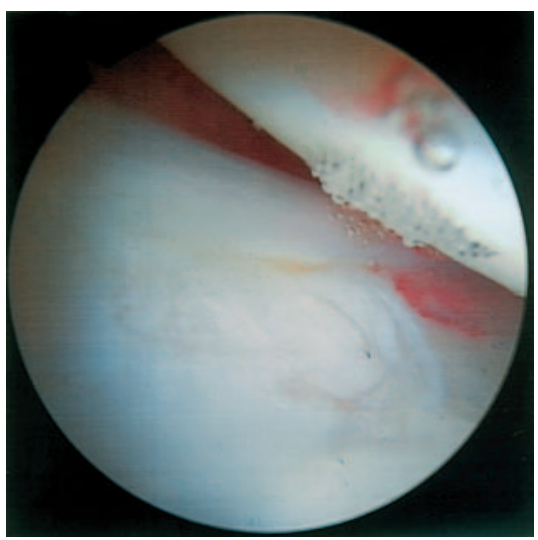

Fig. 1f

Photographs at arthroscopy of the affected hip showing a labral tear and chondral damage in six professional footballers aged a) 32 years (player 1 ); b) 27 years (player 2); c) 32 years (player 3); d) 24 years (player 4); e) 26 years (player 5 ) and f) 28 years (player 6). 
Table II. Results for the six footballers following hip arthroscopy

\begin{tabular}{|c|c|c|c|c|c|c|}
\hline Player & $\begin{array}{l}\text { Radiological } \\
\text { investigation }\end{array}$ & Imaging diagnosis & $\begin{array}{l}\text { CE angle } \\
(\text { Wiberg) })^{7}\left({ }^{\circ}\right)\end{array}$ & $\begin{array}{l}\text { Acetabular } \\
\text { angle }\left({ }^{\circ}\right)\end{array}$ & Operative findings & Size of chondral defect etc. \\
\hline 1 & MRI arthrogram & Labral tear & 42 & 32 & Anterior labral tear & $12 \times 6 \mathrm{~mm}+$ multiple fissures \\
\hline 2 & MRI & None & 42 & 30 & Anterior labral tear & $4 \times 4 \mathrm{~mm}$ stable defect \\
\hline 3 & MRI & Labral tear & 35 & 32 & Anterior labral tear & $15 \times 10 \mathrm{~mm}$ debris + defect \\
\hline 4 & MRI & Labral tear & 32 & 30 & Anterior labral tear & $20 \times 25 \mathrm{~mm}$ unstable defect \\
\hline 5 & CT arthrogram & Labral tear & 38 & 30 & Anterior labral tear & $4 \times 4 \mathrm{~mm}$ stable defect \\
\hline 6 & MRI & Labral tear and chondral defect & 40 & 28 & Anterior labral tear & $5 \times 8 \mathrm{~mm}$ stable defect \\
\hline
\end{tabular}

their dominant side, the leg with which they would normally kick the ball. Two players occupied defence positions, two were mid-field and two were in attack.

Each player was able to give a definite time when an acute injury to his hip had occurred. The pre-operative provocation test was positive for all players. Several had undergone extensive radiological investigation, which included MRI and computed tomographic arthrography (CTA) prior to referral. These techniques had provided the diagnosis of an anterior labral tear in five cases, four on MRI and one on CTA. The MRI of the sixth player was falsely negative. The anteroposterior (AP) radiographs of the pelvis were assessed for dysplasia by measurement of the centre edge (CE) angle of Wiberg ${ }^{7}$ and the acetabular angle. The measurements for all the players were within normal limits.

At arthroscopy each player had an identical injury to the anterior acetabular labrum (Fig. 1) which was classified as a traumatic longitudinal tear. ${ }^{2}$ All had articular chondral defects adjacent to the labral tear visible at arthroscopy. All unstable tissues were resected back to a stable margin. The most significant chondral damage was seen in player 4 (Table II) who required a further operation to stabilise the chondral flap. There were no operative or post-operative complications. All patients were symptomatically improved after surgery, although only five have been able to return to football at the same level.

\section{Discussion}

The acetabular labrum is at risk of injury in the presence of abnormal proximal femoral or acetabular anatomy ${ }^{8}$ or during abnormal loading, as may be seen in the hips of professional sportsmen. ${ }^{9}$

Normal acetabular anatomy was confirmed by measurement of the CE angle and the acetabular angle from preoperative AP radiographs of the pelvis (Table II). In each case, the labral tear was associated with a varying degree of chondral damage, from a small split to a large area of delamination. The severity of this cartilaginous damage appears to affect the length of the rehabilitation period. The only player to have undergone more than one arthroscopy had the most extensive area of articular cartilage damage (player 4). Previous studies have suggested that those patients with acetabular chondral defects do less well in the longer term, ${ }^{5}$ requiring arthroplasty of the affected hip sooner than those with an isolated acetabular labral tear.
Each of our patients was able to describe a specific incident at which the injury had occurred; none was new to professional football at the time of the injury. It has subsequently come to our notice that there are other players, currently playing professional football with acetabular labral injuries, which have been diagnosed on clinical grounds and MR. In common with those players who have had arthroscopy, these others can also identify a specific injury. To date they have been managed by rest, nonsteroidal antiinflammatory medication and intensive physiotherapy enabling them to continue playing but with irregular hip pain.

From the Football Association Injuries Database, ${ }^{1}$ it can be seen that injury to the hip and the structures overlying it, is a significant cause of morbidity. During the 2001/2002 football season, over 800 training days were lost due to injuries to the hip in 64 players. The diagnosis of a labral tear is being increasingly recognised in professional footballers.

The mechanism of injury varied, although a rotational event occurred in all cases. Three players were able to continue playing immediately following the injury but all complained to their training staff of hip pain on the day of the event. No player had debilitating hip pain prior to injury. Four had previously complained of pain in the groin and three had had undergone a hernia repair on the affected side (one bilateral, two unilateral). The repair had not alleviated the symptoms; one player had groin pain at the time of the injury having previously undergone a hernia repair and one player, thought to have a hernia, had relief of his symptoms following the partial labrectomy at arthroscopy of his hip.

Predicting those professional footballers who might be most at risk from labral tears is extremely difficult. In our study the players exhibited neither the abnormal proximal femoral anatomy as seen by Ito et $\mathrm{al},{ }^{4}$ nor the acetabular dysplasia seen in the majority of patients in McCarthy and Lee's study. ${ }^{8}$ The bony structure seen on the radiographs of the pelvis was normal and both CT and MRI scans showed otherwise unremarkable structures around the hip. In association with this, the lack of prodromal symptoms and the ability of all our players to compete at the highest level prior to injury makes the identification of those at risk of this lesion extremely difficult. Within the normal population, acetabular labral tears are seen rarely. The footballers in our study are probably at greater risk due to the nature of their profession. The acute injury to the hip of all six play- 
ers occurred during competitive football or vigorous training. Acetabular labral tears have been documented before in elite athletes, ${ }^{8}$ and the extreme and repetitive forces involved in professional sport are thought to be the contributory factors. The fact that this injury may occur during either routine training or competitive matches limits the ability of sports medicine professionals to protect individual players from it. Awareness of acetabular pathology and the ability to make a rapid diagnosis should facilitate measured management and hasten a return to fitness.

The diagnosis of a labral tear can be made from the detailed history of a rotational injury and the clinical signs which should include a positive provocation test. Although the tear is apparent from some forms of radiological investigation (MRI, CTA), false negatives can occur. MR arthrography has improved diagnostic accuracy. ${ }^{10}$ However, in the presence of a good history and clear signs, arthroscopy can give a definitive diagnosis.

The long-term outcome of these damaged hips remains a cause for concern. Progression of our players to further degeneration is likely because of these early signs of damage. Players with the more severe chondral defects will probably progress to osteoarthritis in the fullness of time.
We would like to thank the players and medical staff at the clubs who gave both their time and expertise. We would also like to thank the staff of the scientific research unit of the English Football Association for advice and information. No benefits in any form have been received or will be received from a commercial party related directly or indirectly to this article.

\section{References}

1. The Football Association Audit of Injuries Database for the $2001 / 2002$ football seasons. The Football Association, Lilleshall National Sports Centre, Shropshire, UK.

2. Lage LA, Patel JV, Villar RN. The acetabular labral tear: an arthroscopic classification. Arthroscopy 1996;12:269-72.

3. Mason J. Acetabular labral tears in the athlete. Clin Sports Med 2001;20:779-90.

4. Ito K, Minka M-A 2nd, Leunig M, Werlen S, Ganz R. Femoroacetabular impingement and the cam-effect: a MRl-based quantitative anatomical study of the femoral head-neck offset. J Bone Joint Surg [Br] 2001;83-B:171-6.

5. Bonnomet $\mathbf{F}$, Lefebevre $\mathbf{Y}$, Clavert $\mathbf{P}$, et al. Arthroscopic treatment of acetabular labrum lesions: a series of 12 patients with a 4-year follow-up. Rev Chir Orthop Reparatrice Appar Mot 2000;86:787-93.

6. Hase T, Ueo T. Acetabular labral tear: arthroscopic diagnosis and treatment. Arthroscopy 1999;15:138-41.

7. Wiberg G. Studies on dysplastic acetabula and congenital subluxation of the hip joint: with special reference to the complication of osteo-arthritis. Acta Chir Scand 1939;83(Suppl):1-135.

8. McCarthy JC, Lee JA. Acetabular dysplasia: a paradigm of arthroscopic examination of chondral injuries. Clin Orthop 2002;405:122-8.

9. McCarthy J, Barsoum W, Puri L, et al. The role of hip arthroscopy in the elite athlete. Clin Orthop 2003;406:71-4.

10. Palmer W. MR arthrography of the hip. Semin Musculoskelet Radiol 1998;2:349-62. 